\title{
DELIMITAÇÃO DE ÁREA DE PROTEÇÃO DAS ÁGUAS SUBTERRÂNEAS NO MUNICÍPIO DE CAPIVARI (SP)
}

\author{
Mara Akie IRITANI \\ Geraldo Hideo ODA \\ Sibele EZAKI \\ Cláudia Luciana VARNIER
}

\begin{abstract}
RESUMO
O Sistema Aqǘfero Tubarão é a principal unidade aqüífera do Município de Capivari e fornece aproximadamente $63,7 \%$ do total de água captada para o abastecimento público. Trata-se de um aqǘfero extremamente heterogêneo, descontínuo, com produtividade variável. Ele vem sendo explorado de forma intensiva, evidenciada pelo rebaixamento da superfície potenciométrica em função do aumento do número de poços na área urbana nas últimas décadas. Este cenário motivou a elaboração de um diagnóstico do potencial hidrogeológico no Município de Capivari, resultando na identificação das áreas com maior produtividade e áreas onde ocorre maior explotação. $\mathrm{O}$ estudo culminou com a proposição e delimitação de áreas de proteção do aqǘfero, que subsidiarão a formulação de uma legislação municipal para a exploração e proteção da água subterrânea.
\end{abstract}

Palavras-chave: Aqüífero Tubarão, áreas de proteção, rebaixamento, produtividade

\section{ABSTRACT}

The Tubarão Aquifer System is the main hydrogeological unit of the Capivari Municipality, State of São Paulo. Approximately $63,7 \%$ of the total public water supply is drawn from it. This system is assumed to be extremely heterogeneous and discontinuous with variable discharge. It has been intensively exploited, as is evidenced by the potentiometric surface drawdown due to the increase of wells drilled in urban areas in recent decades. This scenario motivated the diagnosis of the hydrogeological potential for the Capivari Municipality, which defined areas of greatest productivity and exploitation. This study resulted in the proposal and delimitation of restricted areas of the aquifer, which will be of help for the establishment of municipal laws regarding groundwater exploitation and protection.

Keywords: Tubarão Aquifer, protection areas, drawdown, productivity

\section{INTRODUÇÃO}

A demanda da água subterrânea para abastecimento público vem aumentando significativamente nas últimas décadas em função do crescimento populacional, expansão urbana e processo de industrialização. No Estado de São Paulo, cerca de $60 \%$ dos municípios eram total ou parcialmente abastecidos por recursos hídricos subterrâneos na década de 1990 (SÃO PAULO 1990) e, atualmente, este percentual elevou-se para $80 \%$ (CETESB 2007). Mesmo em regiões onde os aqüíferos apresentam disponibilidade hídrica limitada, este recurso tornou-se importante fonte alternativa e cada vez mais utilizada para os diversos fins.
O Município de Capivari (SP), situado na porção sul da bacia hidrográfica dos rios Piracicaba, Capivari e Jundiaí (Unidade de Gerenciamento de Recursos Hídricos - UGRHI 05), apresenta razoável disponibilidade hídrica com vazões acima da média regional para o aquífero Tubarão (sedimentar), cuja vazão mediana de $7,3 \mathrm{~m}^{3} / \mathrm{h}$ (PEREIRA 1997) é considerada baixa em comparação às demais unidades hidrogeológicas do Estado de São Paulo utilizadas para abastecimento público.

$\mathrm{O}$ maior volume de água produzido anualmente no município, cerca de $60 \%$ (Tabela 1), é proveniente de captações de água subterrânea de 35 poços tubulares do Serviço Autônomo de Água e Esgoto - SAAE. 
TABELA 1 - Volume de água para abastecimento público produzido (superficial e subterrânea) no Município de Capivari.

\begin{tabular}{cccccc}
\hline \multirow{2}{*}{ Ano } & \multicolumn{5}{c}{ Fonte de abastecimento de água } \\
\cline { 2 - 6 } & $\begin{array}{c}\text { Superficial - volume de água } \\
\text { tratada em ETA }\left(\mathrm{m}^{3} / \text { ano }\right)\end{array}$ & $(\%)$ & $\begin{array}{c}\text { Subterrânea } \\
\left(\mathrm{m}^{3} / \text { ano }\right)\end{array}$ & $(\%)$ & $\begin{array}{c}\text { Total }- \text { volume de água } \\
\text { produzido }\left(\mathrm{m}^{3} / \text { ano }\right)\end{array}$ \\
\hline 2007 & 1.482 .600 & 34,42 & 2.824 .490 & 65,58 & 4.307 .090 \\
2008 & 1.801 .340 & 36,28 & 3.163 .390 & 63,72 & 4.964 .730 \\
\hline
\end{tabular}

Fonte: Sistema Nacional de Informações sobre Saneamento - SNIS (2007, 2008).

Estes poços localizam-se predominantemente na área urbana, com o entorno totalmente ocupado pelas mais diversas atividades. A ocupação ao redor dos poços de abastecimento deu-se visando maior proximidade ao público consumidor ou devido à expansão urbana desordenada.

Esta situação de ocupação desordenada e de grande dependência dos mananciais subterrâneos por parte do sistema público de distribuição de água, associada aos indícios de rebaixamento progressivo dos níveis d'água com consequente queda de produtividade de alguns poços, ressalta a necessidade para o estabelecimento de um programa de proteção das águas subterrâneas na região estudada.

Algumas estratégias de proteção são mundialmente difundidas, podendo ser citados trabalhos, técnicas e legislação que visam à implantação de perímetros de proteção de poços e outras captações (USEPA 1991, MERINO \& NAVARRETE 1991, SÃO PAULO 1991, NAVARRETE \& GARCÍA 2003, STROBL \& ROBILLARD 2005, FOSTER et al 2006, entre outros), assim como a definição de zonas de proteção em âmbito mais regional, a partir de mapeamentos de vulnerabilidade à contaminação de aqüíferos (ALLER et al. 1987, FOSTER \& HIRATA 1988, NRC 1993, VRBA \& ZAPOROZEC 1994, IG/CETESB/DAEE 1997, GÁRFIAS et al. 2002, MEAULO 2006, HIRATA \& FERNANDES 2008).

Estas estratégias são voltadas principalmente para a proteção da qualidade da água subterrânea; sob essa ótica, o Instituto Geológico desenvolveu alguns projetos na década de 90 (IG/CETESB/ DAEE 1997; IG 1990, 1991,1993, 1995; HIRATA 1994; IRITANI 1998). Trabalhos recentes visam o desenvolvimento de estratégias de proteção voltadas não apenas à proteção da qualidade da água, mas também da quantidade, associando aos mapeamentos hidrogeológicos a avaliação das produtividades e dos impactos causados pelos bombeamentos intensivos e concentrados nas áreas urbanas (DIAS et al. 2004; FERREIRA et al. 2005).
Estes estudos hidrogeológicos permitem a identificação de áreas críticas e suscetíveis à alteração da qualidade e quantidade das águas subterrâneas, bem como de áreas que merecem ser preservadas em função do seu uso potencial para abastecimento das populações.

Este trabalho apresenta uma metodologia de avaliação hidrogeológica voltada à identificação de áreas potenciais a serem protegidas ou controladas, ilustrando um estudo de caso do Aqüífero Tubarão no Município de Capivari, Estado de São Paulo. Esta metodologia visa contribuir para a aplicação da Deliberação n ${ }^{\circ} 52$ do Conselho Estadual de Recursos Hídricos (SÃO PAULO 2005) que definiu as diretrizes e critérios gerais para o estabelecimento das Áreas de Restrição e Controle da captação e uso das águas subterrâneas.

\section{INSTRUMENTOS LEGAIS PARA PROTEÇÃO DAS ÁGUAS SUBTERRÂNEAS}

O Estado de São Paulo foi pioneiro no Brasil no estabelecimento de uma lei de proteção das águas subterrâneas, a Lei nº 6.134, de 02 de junho de 1988 (SÃO PAULO 1988), o que chamou a atenção para a necessidade de regulação da explotação e proteção deste recurso por sua importância estratégica para o abastecimento da população paulista.

Nas últimas décadas, como conseqüência do desenvolvimento econômico e populacional do Estado, da escassez e deterioração da qualidade das águas superficiais e dos avanços tecnológicos na perfuração de poços, a explotação de água subterrânea tem aumentado expressivamente, inclusive para uso no sistema público de abastecimento de água (CETESB 2007). O total de poços existentes no Estado de São Paulo é um número desconhecido, mas estudos de FERREIRA et al. (1996), IG (1991) e IG (1993) mostram que a partir dos anos 80 , há um aumento significativo na quantidade de poços perfurados a cada década, inclusive na região de Capivari (VARNIER et al. 2005). 
O Decreto Estadual $n^{\circ} 32.955$, de 7 de fevereiro de 1991, que regulamentou a Lei $\mathrm{n}^{\circ} 6.134 / 88$, instituiu as Áreas de Proteção como instrumentos para o estabelecimento de medidas de controle em áreas de interesse para conservação do equilíbrio natural das águas subterrâneas e manutenção dos serviços de abastecimento de água (SÃO PAULO 1991).

Uma das categorias de Área de Proteção estabelecida por esse decreto é a Área de Restrição e Controle, que compreende uma região onde há necessidade de disciplinar as extrações de água e controlar ou restringir empreendimentos potencialmente poluidores.

Para subsidiar sua implantação, em 2005 foi aprovada a Deliberação CRH n ${ }^{\circ} 52$, de 15 de abril de 2005 (SÃO PAULO 2005), que instituiu as diretrizes e procedimentos gerais para o estabelecimento de uma Área de Restrição e Controle da captação e uso das águas subterrâneas.

$\mathrm{O}$ estudo hidrogeológico deve ser a base técnica para a delimitação da Área de Restrição e Controle, que poderá ser classificada em:

- Área Potencial de Restrição e Controle (ARC-PO), onde a densidade de poços e o volume extraído indicam super-explotação ou existem/ existiram atividades potencialmente contaminadoras do solo e da água subterrânea;

- Área Provável de Restrição e Controle (ARC-PR) onde se observam indícios de super-explotação e interferência entre poços ou são observados indícios de contaminação no solo e água subterrânea;

- Área Confirmada de Restrição e Controle (ARC-CO), onde há a constatação de super-explotação ou contaminação da água subterrânea.

A proposição da Área de Restrição e Controle pode ser realizada pelos órgãos de controle ambiental, de recursos hídricos e de saúde ou pelo Comitê da Bacia Hidrográfica, mas o ato declaratório é de responsabilidade do Conselho Estadual de Recursos Hídricos (CRH).

\section{CARACTERIZAÇÃO DA ÁREA}

A área de estudo abrangeu o Município de Capivari, em especial a área urbana e arredores, onde se concentram os poços destinados ao sistema público de abastecimento de água.

O Município de Capivari situa-se na porção centro-leste do Estado de São Paulo (Figura 1), distante cerca de $130 \mathrm{~km}$ da capital paulista, entre as coordenadas 231 e $254 \mathrm{~km}$ Oeste e 7.440 e 7.470 km Sul. Os principais acessos são pela Rodovia Castelo Branco (SP - 280) e Rodovia do Açúcar (SP - 308).

O município está na bacia hidrográfica do rio Capivari, que se insere na Unidade de Gerenciamento de Recursos Hídricos (UGRHI) dos rios Piracicaba/Capivari/Jundiaí (UGRHI-5).

\subsection{Aspectos geológicos}

O Município de Capivari insere-se em contexto de borda da Bacia Sedimentar do Paraná, na Depressão Periférica Paulista, onde afloram os sedimentos dos Grupos Tubarão, Passa Dois e São Bento, com ocorrências de rochas intrusivas básicas (sills ou diques) e materiais de cobertura cenozóica (DAEE/UNESP 1980, IPT 1981).

$\mathrm{Na}$ área do município, o Grupo Tubarão (Figura 1) é representado por rochas sedimentares do Subgrupo Itararé, que ocorrem em quase toda a extensão da área estudada. Esta unidade é composta por uma predominância de arenitos com granulometria variada, por vezes arcoseanos e/ou conglomeráticos, diamictitos, siltitos, folhelhos e ritmitos (PETRI \& PIRES 1992, PIRES \& PETRI 1993, PETRI et al. 1996).

Segundo o modelo de sedimentação admitido para a região (PIRES \& PETRI 1991, PETRI 1992, PIRES 2001), estas litologias foram depositadas por fluxos marinhos de detritos provenientes de um continente emerso, situado a nordeste da área.

Sobrejacente ao Subgrupo Itararé, com ocorrência a noroeste do município, encontra-se a Formação Tatuí, caracterizada por depósitos marinhos, constituídos predominantemente por siltitos, arenitos finos, calcários e sílex. Em sua base, apresenta relações de discordância erosiva com o Subgrupo Itararé, podendo localmente possuir conglomerado basal.

Sobrepostas ao Grupo Tubarão, com ocorrência restrita a noroeste do município, encontram-se as rochas do Grupo Passa Dois, representado na região pelas formações Estrada Nova e Irati, compostas predominantemente por sedimentos finos.

Rochas ígneas intrusivas básicas, representadas por corpos de diabásio, surgem de forma irregular na área do município de Capivari, nas porções oeste e no centro-norte, principalmente.

Coberturas cenozóicas indiferenciadas, constituídas por arenitos finos a médios pouco consolidados e sedimentos de depósitos de coluviais e aluviais ocorrem nas porções norte e sul da cidade. 


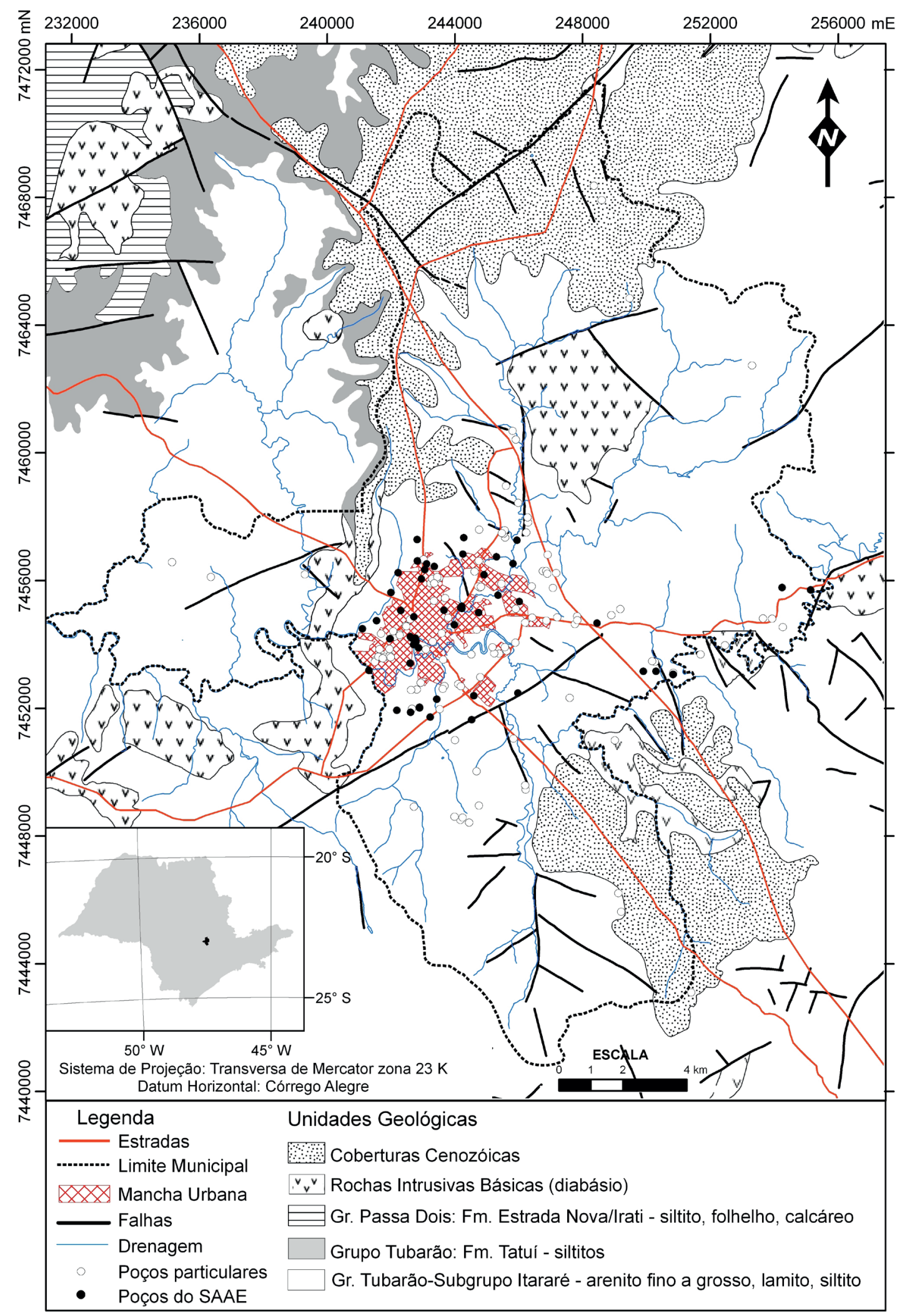

FIGURA 1 - Mapa geológico do Município de Capivari e localização dos poços cadastrados. Fonte: DAEE/UNESP (1980). 


\subsection{Aspectos hidrogeológicos}

$\mathrm{Na}$ área do município distinguem-se duas unidades hidrogeológicas principais: Sistema Aqǘfero Tubarão e Aqüífero Diabásio. O primeiro é representado por sedimentos do Subgrupo Itararé e o segundo, por sills ou diques de diabásio, sendo ambos heterogêneos, descontínuos e anisotrópicos. Poucos são os estudos hidrogeológicos da área, podendo ser citados os de DAEE (1981), STEVAUX et al. (1987), ODA et al. (1993), VIDAL (2002), DAEE/IG/IPT/CPRM (2005), ODA et al. (2005), VARNIER et al. (2005) e VIDAL et al. (2005).

O Sistema Aqüífero Tubarão (SAT) é granular, de porosidade primária e apresenta condições de semiconfinamento a livre. A circulação e o armazenamento de água estão associados tanto aos poros existentes nas rochas como às descontinuidades estruturais (juntas, fraturas ou falhas).

Considerando 765 poços de toda faixa aflorante do SAT no Estado de São Paulo, a capacidade específica $(\mathrm{Q} / \mathrm{s})$ mediana deste aqüífero é de 0,11 $\mathrm{m}^{3} / \mathrm{h} / \mathrm{m}$ (DAEE/IG/IPT/CPRM 2005).

DAEE (1981) obteve valores de transmissividade (T) entre 0,3 e $40 \mathrm{~m}^{2} /$ dia e duas classes para os valores de condutividade hidráulica (K): $0,002 \mathrm{a}$ $0,024 \mathrm{~m} /$ dia e 0,055 a $0,7 \mathrm{~m} /$ dia.

Comparando com outros sistemas aqüíferos no Estado de São Paulo, o SAT apresenta regionalmente as menores produtividades, mas por ocorrer em regiões com baixa disponibilidade hídrica esta unidade hidrogeológica passa a ter importância ao abastecimento como fonte complementar.

O Aqüífero Diabásio (AD) ocorre de forma irregular na área; sua porosidade é secundária, isto é, a água circula pelas fraturas e fissuras abertas formadas após a consolidação da rocha, que geralmente fornecem pouca água. No Município de Capivari, a maioria dos poços não explora água deste aqüífero, o que inviabiliza a avaliação de suas características hidráulicas no local.

As coberturas cenozóicas compõem uma unidade aqüífera pouco explorada para o abastecimento público devido à pequena espessura, inferior a 30 metros, sendo utilizada principalmente por poços rasos, escavados.

\section{MATERIAIS E MÉTODOS}

O estudo hidrogeológico para fins de delimitação de áreas de proteção do SAT foi desenvolvido fundamentalmente em duas etapas. A primeira consistiu no levantamento e tratamento de dados de poços para obtenção de parâmetros hidráulicos e confecção de mapas temáticos como os de potenciometria, capacidade específica, vazão, transmissividade e condutividade hidráulica. A segunda etapa consistiu na integração dos dados gerados na avaliação da produtividade potencial do SAT com as características geológicas da área, mapas potenciométricos, localização de poços e distribuição da ocupação urbana, para obter o zoneamento.

O levantamento de dados e informações de poços tubulares de Capivari foi realizado junto aos bancos de dados do Instituto Geológico - IG/ SMA, do Departamento de Águas e Energia Elétrica (DAEE) e das empresas privadas de perfuração mais atuantes na área. Trabalhos de campo foram efetuados para complementação e atualização de dados, bem como para obtenção de coordenadas dos poços (Sistema de Projeção UTM, datum Córrego Alegre, zona 23S) com auxílio de aparelho GPS, modelo Garmin MAP 76CSx, com erro de precisão de 4 metros. Dos 177 poços levantados, 168 foram georeferenciados e locados em folhas topográficas na escala 1:10.000 da SECRETARIA DE ECONOMIA E PLANEJAMENTO DO ESTADO DE SÃO PAULO (1977a, b; 1979a, b).

Os dados foram incorporados ao cadastro digital de poços do IG/SMA. A partir de parâmetros hidráulicos (nível estático - NE, nível dinâmico - ND, vazão - Q) e dados relacionados ao poço (geologia, cota, profundidade, etc.) foram determinadas outras variáveis como rebaixamento (s), capacidade específica $(\mathrm{Q} / \mathrm{s})$, espessura saturada do aqüífero (b), altitude do nível d'água. Foram utilizados métodos estatísticos clássicos (máximo, mínimo, média e mediana) para o tratamento dos dados hidrogeológicos do SAT.

$\mathrm{O}$ cálculo de transmissividade $(\mathrm{T})$ e condutividade hidráulica (K) foi realizado a partir de planilhas de dados de 34 testes de bombeamento (rebaixamento e recuperação versus tempo). A quase totalidade dos testes ocorreu a um tempo de bombeamento de 24 horas, mantendo-se a vazão constante sempre que possível. As interpretações dos testes foram feitas através do programa Aquifer Test versão 2.52 (Waterloo Hydrogeologic Inc.). Adotou-se um valor de $0,10 \mathrm{~m}$ para representar a distância (r) entre os poços de bombeamento e de observação. Por não haver dados de poços de observação, não foi possível avaliar o coeficiente de armazenamento do aqüífero e a velocidade da água subterrânea. 
Com o intuito de avaliar a distribuição espacial dos parâmetros hidráulicos do SAT e correlacioná-los ao contexto hidrogeológico local, foram elaborados mapas de isovalores de T, K, Q/s e Q utilizando-se o programa Surfer versão 8,0 (Golden Software Inc.). Os métodos de interpolação selecionados foram a krigagem e o inverso do quadrado da distância, considerando raios de busca de 2.000 a $5.000 \mathrm{~m}$. Estes mapas foram traçados apenas para a porção central do município onde se concentram os poços; no restante da área a escassez de dados impossibilitou o estudo do comportamento do aqüífero.

Foram confeccionados mapas potenciométricos para diferentes períodos (anterior a 1984; 1984 1995 e 1995-2006) visando avaliar as tendências da superfície potenciométrica face ao aumento do número de captações, principalmente no centro urbano. A seleção desses períodos baseou-se na evolução das perfurações de poços ao longo dos anos.

Finalmente, a delimitação da área de proteção foi realizada considerando: (1) as regiões com maior rebaixamento do nível da água observadas nos mapas potenciométricos, coincidentes com a maior densidade de poços e adensamento urbano, (2) as áreas de maior produtividade potencial, identificadas nos mapas de isovalores de capacidade específica, vazão, condutividade hidráulica e transmissividade e (3) a área de ocorrência do Aqǘfero Tubarão, usando mapa geológico e perfis dos poços.

A análise integrada dos dados permitiu a delimitação da área de proteção, utilizando recursos do programa ArcGIS versão 9.2 (ESRI). Os limites desta área foram ajustados às feições físiográficas do terreno (drenagens e divisores de água) e acessos (estradas e ruas).

\section{RESULTADOS}

\subsection{Características gerais dos poços}

Foram cadastrados até dezembro/2006 177 poços tubulares, ativos e alguns desativados, em Capivari, dos quais 49 pertencem ao SAAE e o restante (128) a usuários privados. Os registros obtidos indicam que a atividade de explotação de água foi iniciada na década de 50 e que houve um aumento significativo no número de poços a partir do início da década de 70, atingindo o máximo no período de 1990 a 1994 quando foram perfurados 43 poços (25\% do total de poços cadastrados) (Figura 2).

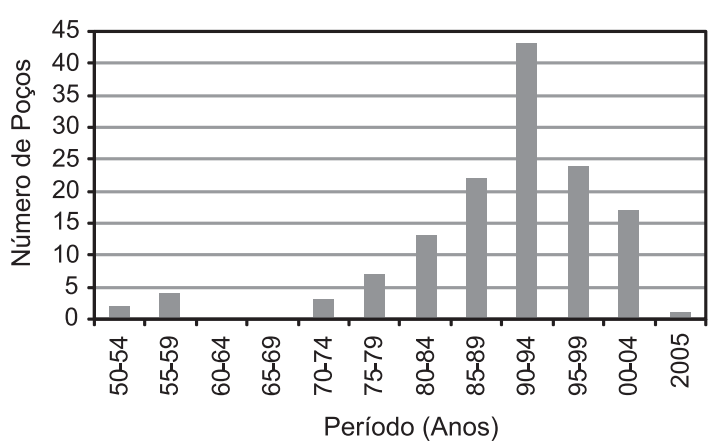

FIGURA 2 - Evolução das perfurações de poços tubulares ao longo dos anos no Município de Capivari (Período de 1950 a 2005).

A profundidade média dos poços da região, obtida a partir de 146 poços, é de $205 \mathrm{~m}$. Considerando os intervalos de profundidade dos poços (Figura 3), constata-se que, de modo geral, o número de poços decai com o aumento da profundidade, exceto para o intervalo de 251 a $300 \mathrm{~m}$, onde há um incremento no número de poços. Esses poços mais profundos pertencem, em sua maioria, ao SAAE, responsável pelo sistema público de abastecimento de água, e também apresentam maiores vazões de explotação, em média duas vezes maior que os poços de usuários privados, mais rasos.

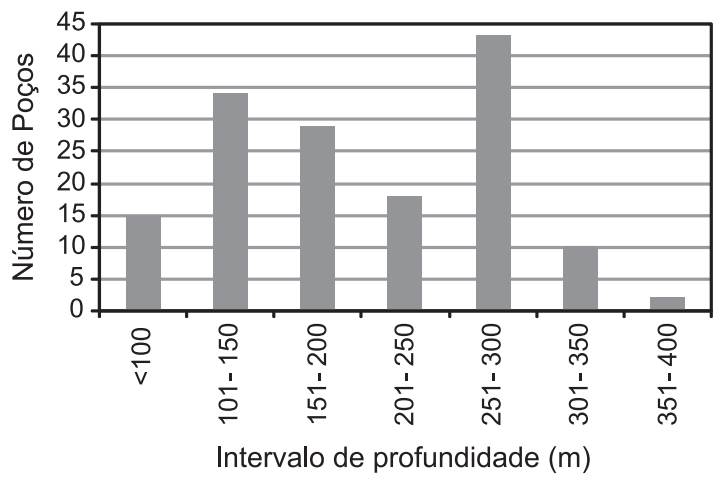

FIGURA 3 - Número de poços por intervalo de profundidade.

Os valores médios e medianos de nível estático, nível dinâmico, rebaixamento, vazão e capacidade específica são apresentados na tabela 2 . 
TABELA 2 - Valores médios dos parâmetros hidráulicos do SAT em Capivari.

\begin{tabular}{lccccc}
\hline Parâmetro & $N^{o}$ Poços & Mínimo & Máximo & Média & Mediana \\
\hline Nível Estático (m) & 113 & 0,0 & 148,0 & 44,10 & 38,00 \\
Nível Dinâmico (m) & 110 & 43,0 & 192,0 & 105,80 & 99,90 \\
Rebaixamento (m) & 110 & 5,9 & 144,0 & 61,4 & 59,2 \\
Vazão $\left(\mathrm{m}^{3} / \mathrm{h}\right)$ & 142 & 0,50 & 80,00 & 12,25 & 9,75 \\
$\begin{array}{l}\text { Capacidade Específica } \\
\left(\mathrm{m}^{3} / \mathrm{h} / \mathrm{m}\right)\end{array}$ & 110 & 0,005 & 2,010 & 0,278 & 0,160 \\
\hline
\end{tabular}

\subsection{Potenciometria e fluxo da água subterrânea}

A superfície potenciométrica do SAT em Capivari foi anteriormente estudada por ODA et al. (1993), que indicaram que os fluxos das águas subterrâneas na região mais urbanizada do município e arredores seguiam para uma grande depressão alongada com direção NNE-SSW. Tal comportamento era ocasionado pela concentração de poços no local, provocando um decréscimo progressivo da superfície potenciométrica ao longo do tempo.

Este fato foi reavaliado a partir do maior número de poços na mesma região. Para ilustrar este cenário, foram confeccionados três mapas potenciométricos considerando três épocas diferentes: anterior a 1984 (Figura 4a), de 1985 a 1994 (Figura 4b) e de 1995 a 2006 (Figura 4c).

Esses intervalos de tempo foram definidos com base na evolução das perfurações ao longo do tempo (Figura 2).

No primeiro período havia pequena quantidade de poços e a superfície potenciométrica não devia apresentar mudanças significativas devido ao bombeamento, refletindo melhor as condições naturais; nesse caso foram considerados todos os poços anteriores a 1984 .

No período de 1985 a 1994 observa-se um incremento expressivo na quantidade de poços construídos no município, que deve ter influenciado a superfície potenciométrica da época.

O último período inclui os poços perfurados após 1995, buscando refletir a superfície potenciométrica atual da região.

Os mapas indicaram uma queda geral dos níveis estáticos em algumas áreas do aqüífero, o que levou à redução da produtividade dos poços, ao consequente aprofundamento ou abandono dos mesmos e à perfuração de novos poços mais profundos para suprir as demandas sempre crescentes.
Na figura 4a observa-se apenas uma pequena área rebaixada (R1), de pequena importância e pouco preocupante. Na figura $4 \mathrm{~b}$ já ocorrem duas áreas (R2 e R3) alinhadas na direção NE-SW, certamente resultantes de bombeamentos excessivos dos poços. Finalmente, na figura $4 \mathrm{c}$ observa-se uma expansão da área rebaixada (R4), aprofundando ainda mais a superfície potenciométrica do local. Nesta porção, os níveis estáticos dos poços são bastante profundos, abaixo da altitude $470 \mathrm{~m}$. Analisando também a figura 1, observa-se que justamente na área rebaixada há uma grande densidade de poços, a maioria pertencente ao SAAE, cujos poços apresentam maiores vazões de explotação.

\subsection{Transmissividade e condutividade hidráulica}

Os valores de transmissividade ( $\mathrm{T}$ ) e condutividade hidráulica $(\mathrm{K})$ foram obtidos através da interpretação de 34 testes de bombeamento pelos métodos de Neuman e Hantush. Supõe-se aqui, com base na constituição litológica, que o aqüífero possui um comportamento livre a localmente confinado, apesar dos tempos de bombeamento e a conformação das curvas de rebaixamento dos testes não serem suficientes para a confirmação destas características.

A transmissividade do SAT na região variou de $8,8 \times 10^{-7}$ a $2,6 \times 10^{-4} \mathrm{~m}^{2} / \mathrm{s}$ com média de $3,3 \times 10^{-5}$ $\mathrm{m}^{2} / \mathrm{s}$. A condutividade hidráulica apresentou valores de $1,1 \times 10^{-8}$ a $1,1 \times 10^{-6} \mathrm{~m} / \mathrm{s}$ com média de $1,5 \times 10^{-7}$ $\mathrm{m} / \mathrm{s}$. Estes valores apresentam um grande intervalo de variação, mas estão concordantes com aqueles encontrados no estudo regional de DAEE (1981), denotando a grande heterogeneidade que caracteriza o Sistema Aqüífero Tubarão no Estado de São Paulo.

A distribuição espacial da $\mathrm{T}$ pode ser observada na figura $5 \mathrm{a}$, onde se nota um aumento na direção noroeste da cidade. Na figura $5 b$, a condutividade hidráulica $(\mathrm{K})$ mostra o mesmo comportamento da transmissividade (T), com aumento dos valores na direção NW. 


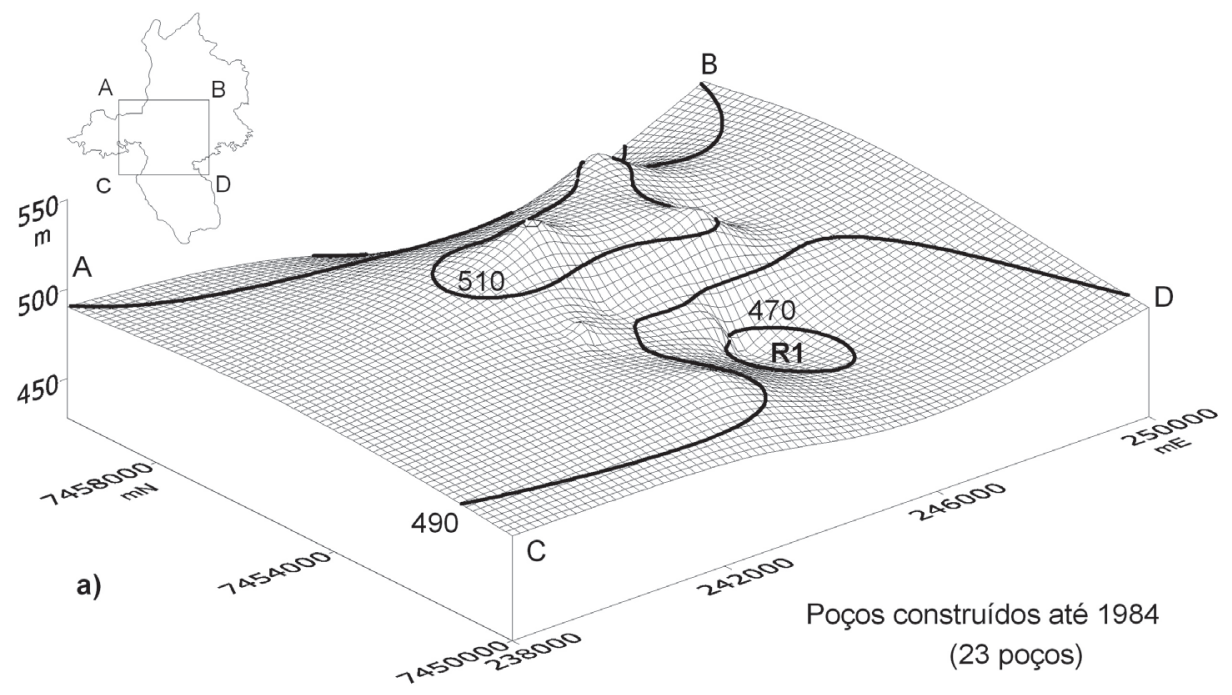

B

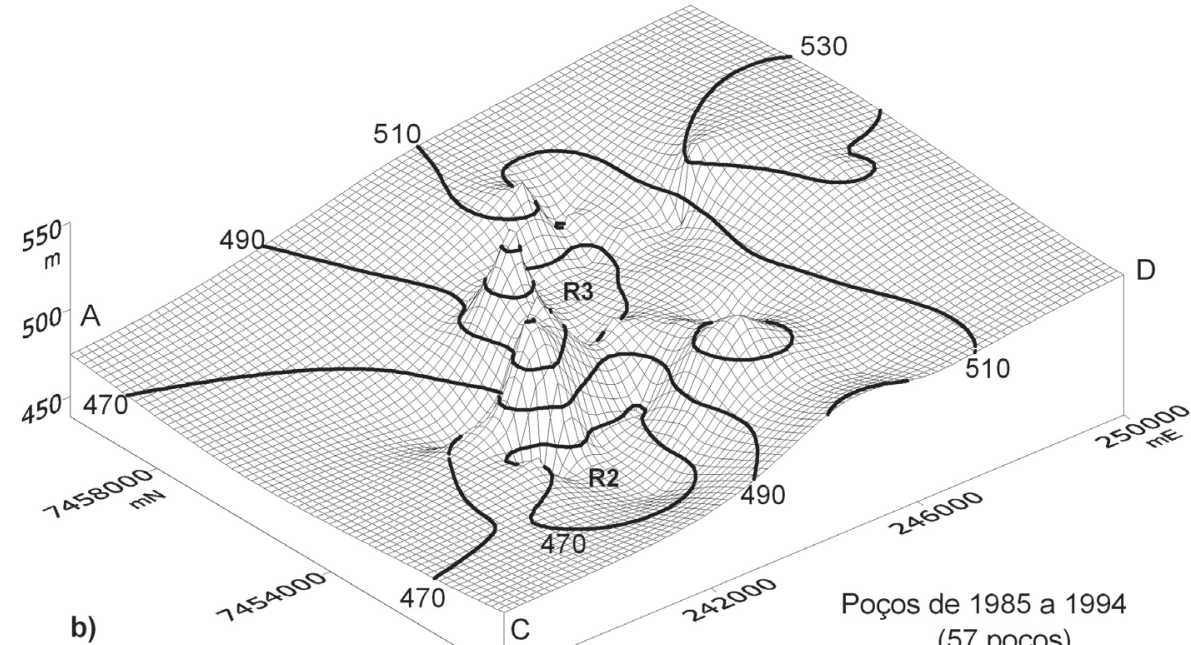

b)

C

(57 poços)

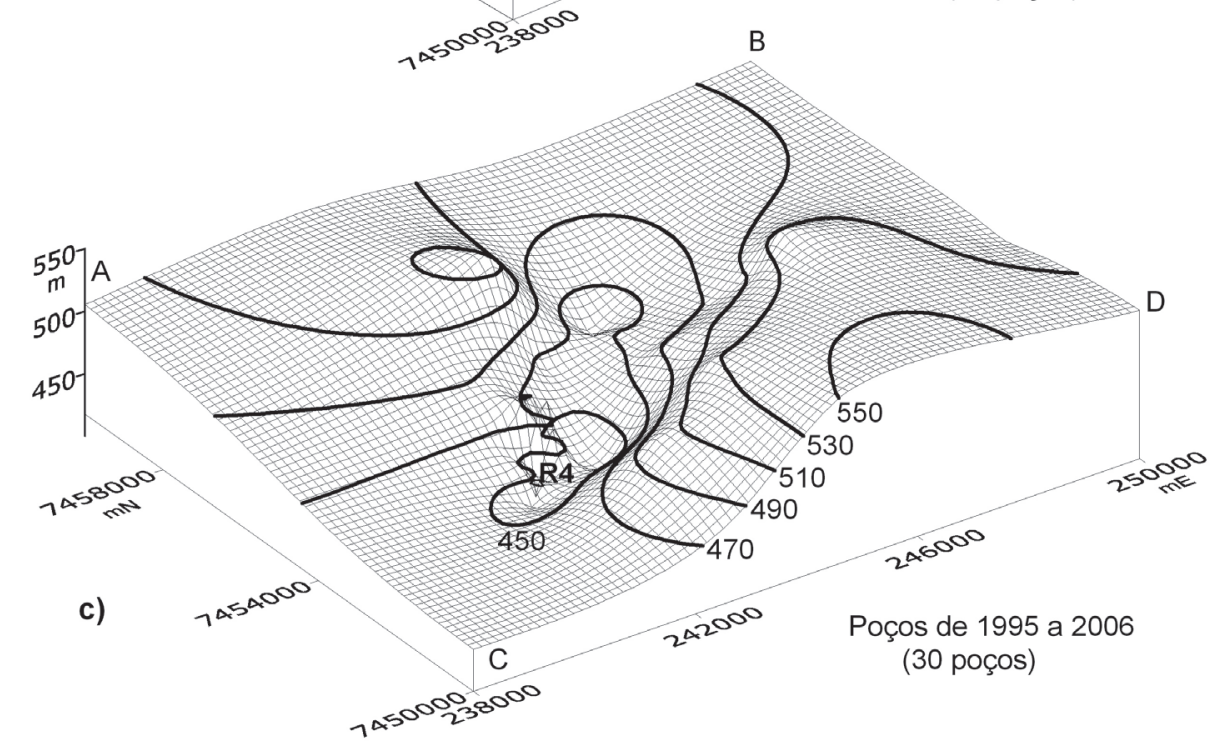

FIGURA 4 - Evolução da superfície potenciométrica na porção central de Capivari (SP). 

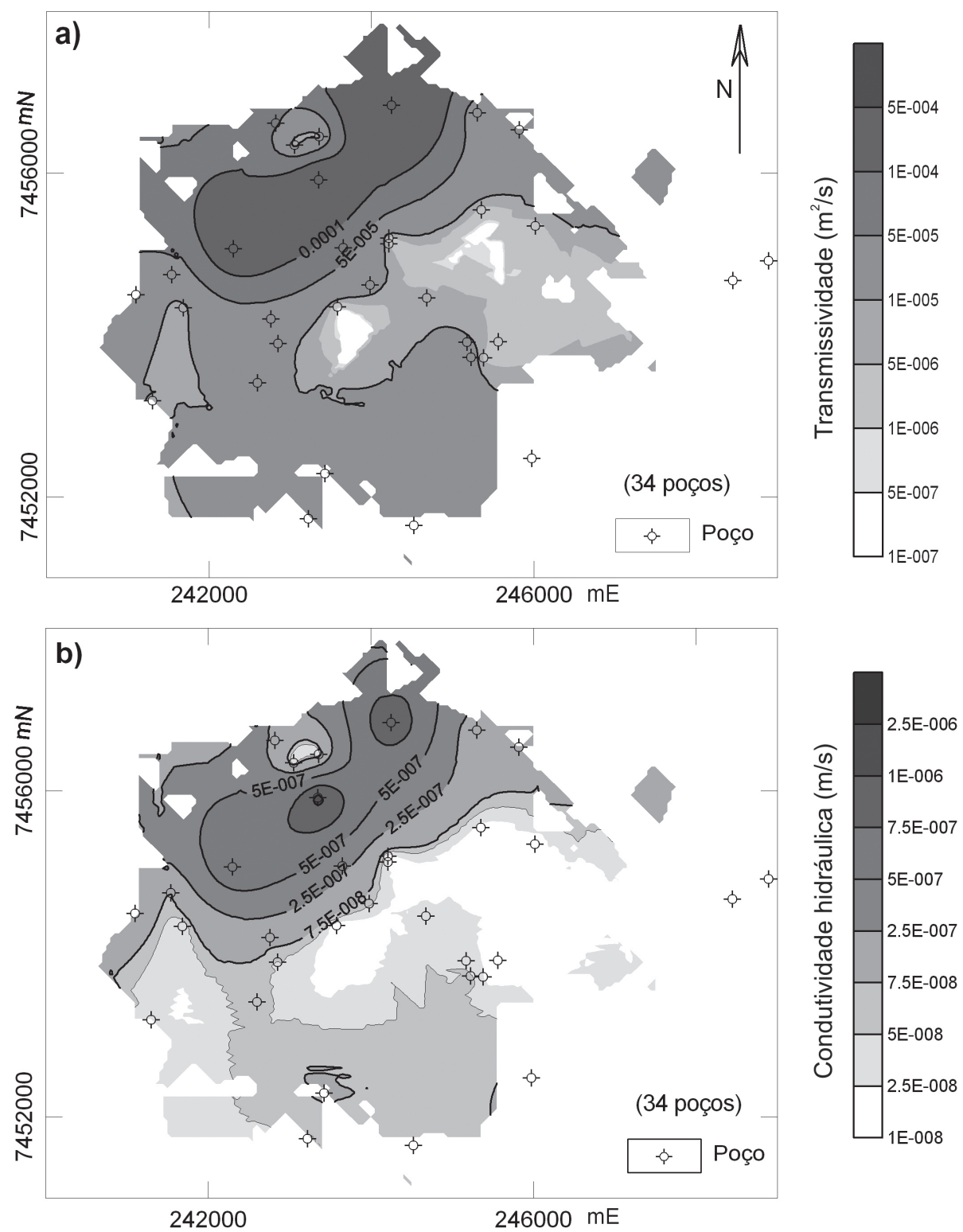

FIGURA 5 - Mapas de isovalores de transmissividade (a) e condutividade hidráulica (b) na porção central do Município de Capivari (SP).

\subsection{Produtividade dos Poços}

Os valores de média $\left(12,25 \mathrm{~m}^{3} / \mathrm{h}\right)$ e mediana $\left(9,75 \mathrm{~m}^{3} / \mathrm{h}\right)$ de vazão dos poços de Capivari encontram-se acima da média regional de $7,3 \mathrm{~m}^{3} / \mathrm{h}$, encontrada por PEREIRA (1997) para o SAT. As capacidades específicas apresentam média $(0,278$ $\left.\mathrm{m}^{3} / \mathrm{h} / \mathrm{m}\right)$ e mediana $\left(0,16 \mathrm{~m}^{3} / \mathrm{h} / \mathrm{m}\right)$ mais elevadas do que o valor médio $\left(0,11 \mathrm{~m}^{3} / \mathrm{h} / \mathrm{m}\right)$ do SAT encontrado por DAEE/IG/IPT/CPRM (2005), de- monstrando boa produtividade deste aquifero em Capivari.

Para análise da produtividade local do aqüífero foram confeccionados mapas de isovalores de capacidade específica $(\mathrm{Q} / \mathrm{s})$ considerando três intervalos de profundidades: poços até $150 \mathrm{~m}$ (Figura 6a), de 151 a $250 \mathrm{~m}$ (Figura 6b) e de 251 a $400 \mathrm{~m}$ (Figura 6c). Os valores médios, medianos, mínimos e máximos por intervalo de profundidade são apresentados na tabela 3 . 
TABELA 3 - Dados de capacidade específica $\left(\mathrm{em}^{3} / \mathrm{h} / \mathrm{m}\right)$ por intervalo de profundidade de poço para o SAT em Capivari.

\begin{tabular}{cccccc}
\hline Intervalo de Profundidade & $N^{\circ}$ Poços & Mínimo & Máximo & Média & Mediana \\
\hline Até $150 \mathrm{~m}$ & 34 & 0,020 & 0,580 & 0,164 & 0,140 \\
$151-250 \mathrm{~m}$ & 40 & 0,005 & 1,550 & 0,218 & 0,105 \\
$251-400 \mathrm{~m}$ & 36 & 0,020 & 2,010 & 0,452 & 0,305 \\
\hline
\end{tabular}

O primeiro intervalo de profundidade que corresponde à porção superior do aqüífero é pouco produtivo. Somente quatro poços apresentaram valores de Q/s superiores a $0,2 \mathrm{~m}^{3} / \mathrm{h} / \mathrm{m}$ (área Qs1 da figura 6a). Considerando os poços com profundidades entre 151 e $250 \mathrm{~m}$, destacam-se duas pequenas áreas, uma na porção nordeste do município e outra na porção sudeste, com produtividade baixa a média (área Qs2 da figura 6b). Para os poços mais profundos (251 a $400 \mathrm{~m}$ ), foram encontradas três áreas (Qs3, Qs4 e Qs5 da figura 6c) de média a alta produtividade, onde os valores de $\mathrm{Q} / \mathrm{s}$ são superiores a $0,8 \mathrm{~m}^{3} / \mathrm{h} / \mathrm{m}$, indicando a melhor produtividade na porção inferior do aqüífero a norte, a oeste e a sul, e extrapolando a mancha urbana.

Foi também elaborado um mapa de vazões (Figura 7), cujas áreas de maior produção são compatíveis com aquelas de maior capacidade específica.
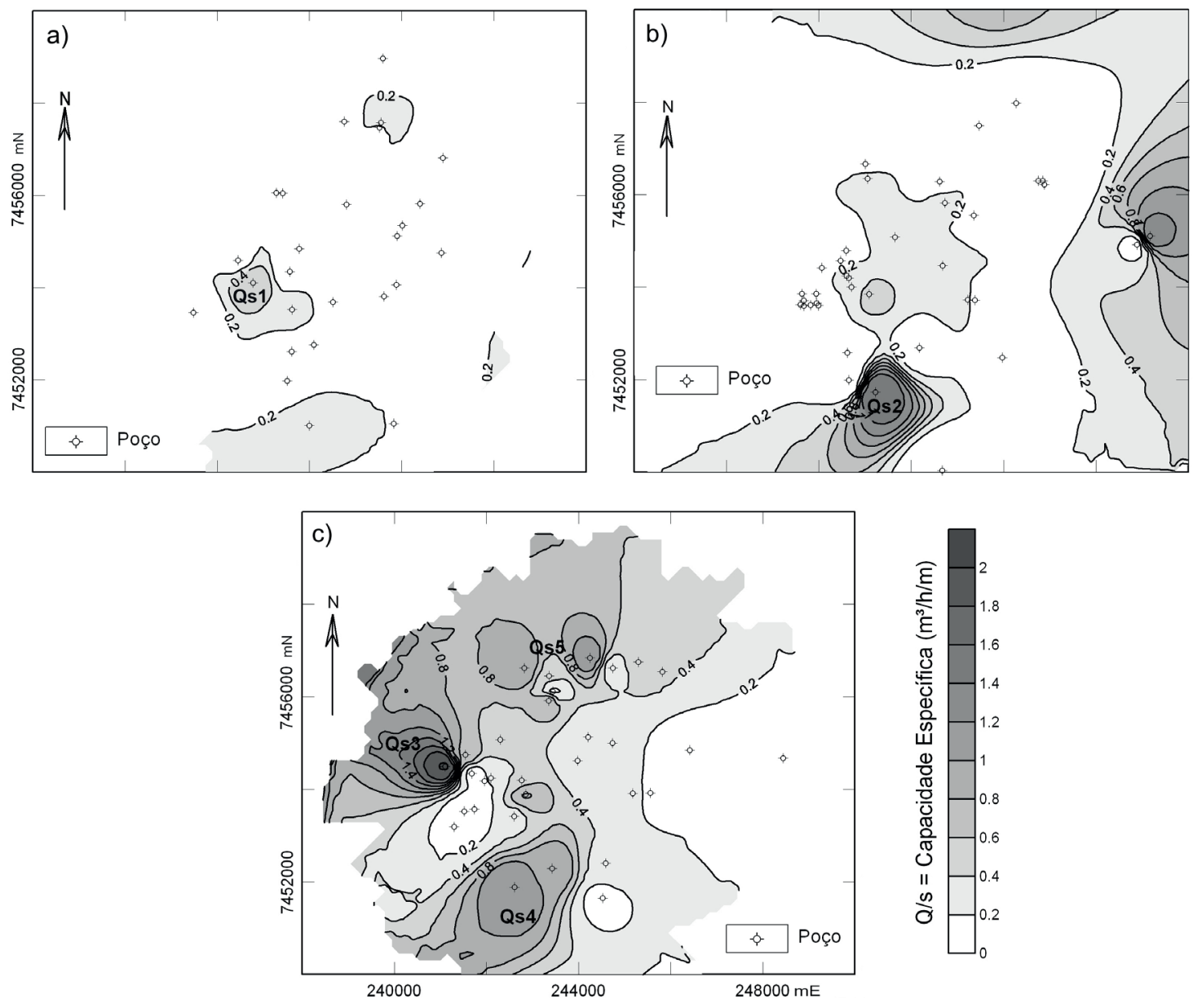

FIGURA 6 - Mapas de isocapacidade específica gerados a partir de poços com profundidades: até $150 \mathrm{~m}$ (a); de 151 a 250 m (b); de 251 a 400 m (c). Áreas produtivas: Qs1, Qs2, Qs3, Qs4, Qs5. 


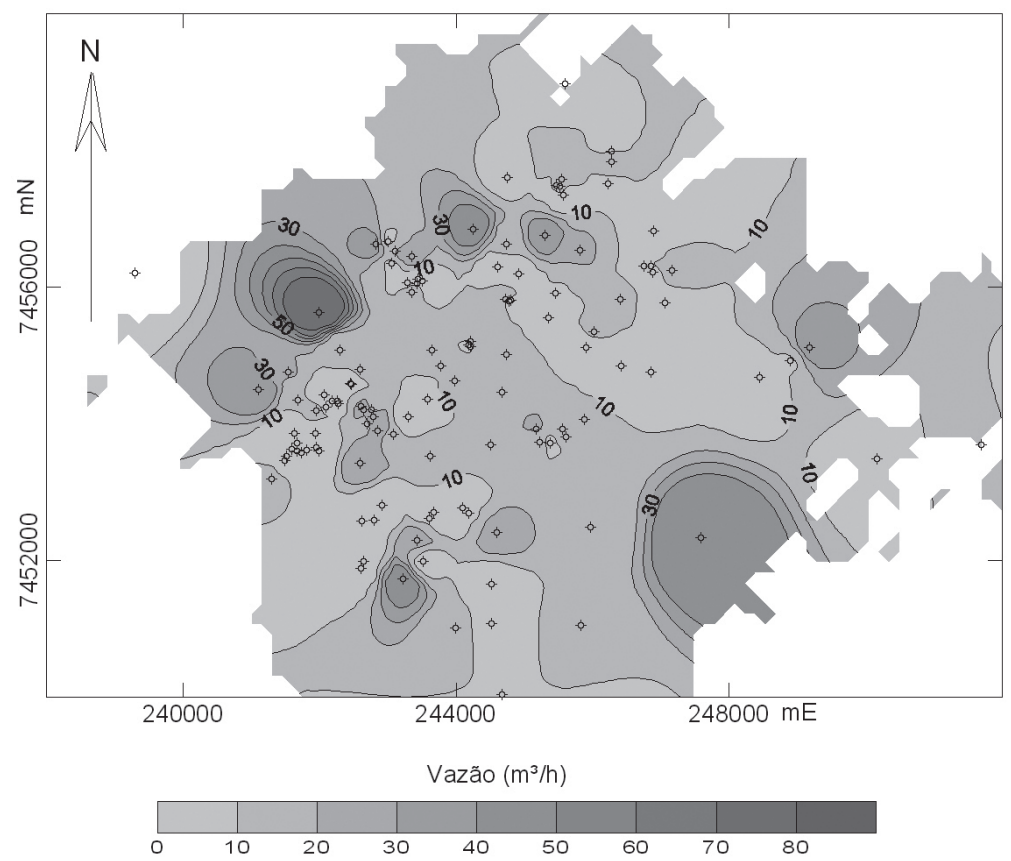

FIGURA 7 - Mapa de distribuição de vazões dos poços de Capivari.

\section{DISCUSSÃO}

Para a delimitação da área de proteção de águas subterrâneas foi realizada a identificação e avaliação integrada das regiões que apresentaram melhor produtividade potencial do aqüífero, evidências de rebaixamento e grande concentração de poços destinados ao abastecimento público.

A partir dos mapas potenciométricos foram delimitadas porções mais rebaixadas do nível estático, considerando a evolução da superfície potenciométrica do SAT nos três períodos analisados. Estas porções concentram-se na área urbana central de Capivari, como ilustrado na figura 8 .

Áreas de maior produtividade em água foram delimitadas com base nos mapas de isovalores de Q/s, Q, T e K, levando em consideração os valores médios e do terceiro quartil desses respectivos parâmetros (Figura 8).

Considerando a importância da água subterrânea no abastecimento da população de Capivari, a área de proteção proposta para o SAT foi delimitada enfocando dois objetivos principais: 1) minimizar o impacto gerado pelo bombeamento intensivo dos poços na região central da cidade, que vem causando rebaixamento do nível da água, e 2) proteger regiões do aqüífero com boa produtividade potencial, visando evitar impactos ao nível e qualidade da água e reservá-la de modo a atender a futuras demandas de água.

Avaliando integradamente as particularidades hidrogeológicas de cada porção da área de proteção proposta (Figura 8), estabeleceu-se o contorno de três zonas distintas, conforme ilustrado na figura 9.

A Zona 1 corresponde a uma faixa que se estende na direção nordeste-sudoeste passando pela porção central da cidade; é caracterizada pelo adensamento urbano intenso, pela concentração de parte dos poços destinados ao sistema público de abastecimento de água e pelo rebaixamento da superfície potenciométrica.

O limite desta zona foi definido principalmente em função das áreas de maior rebaixamento das cotas potenciométricas. A interferência e somatória dos cones de rebaixamento dos poços localizados de forma concentrada apenas na área urbana, associado a regimes de bombeamento intensivos e prolongados, são responsáveis por essas depressões da superfície potenciométrica.

As cotas potenciométricas do período 19851994 mostravam, nas porções nordeste e centro-sul desta zona,valores em torno de $490 \mathrm{~m}$ e $470 \mathrm{~m}$, respectivamente. No período seguinte (1995-2006) as cotas potenciométricas estimadas nestas regiões mostraram um rebaixamento de cerca de 20 metros. 
A produtividade potencial da Zona 1 é baixa a média com valores de $\mathrm{Q} / \mathrm{s}$, em geral, inferiores a $0,3 \mathrm{~m}^{3} / \mathrm{h} / \mathrm{m}$ e transmissividade predominantemente inferior a $5,0 \times 10^{-5} \mathrm{~m}^{2} / \mathrm{s}$. Na porção noroeste desta zona, os valores de capacidade específica de poços com mais de $250 \mathrm{~m}$ são mais elevados, indicando melhor produtividade potencial a maiores profundidades.

Para minimizar os impactos causados pelo bombeamento intensivo, recomenda-se a restrição à perfuração de novos poços e do aprofundamento daqueles existentes, bem como permitir somente a substituição dos poços destinados ao sistema pú- blico de abastecimento de água. Os volumes extraídos dos poços devem ser reduzidos tanto quanto possível, seja diminuindo a vazão dos poços e/ou otimizando o regime de bombeamento, de forma a promover uma recuperação do nível da água e evitar cones profundos de rebaixamento.

A Zona 2 abrange a porção noroeste da cidade e parte da bacia hidrográfica do Córrego Engenho Velho, limitando-se a leste com a Zona 1, e caracteriza-se pela produtividade potencial significativa, explorada por poços destinados ao sistema público de abastecimento, com avanço da ocupação urbana.

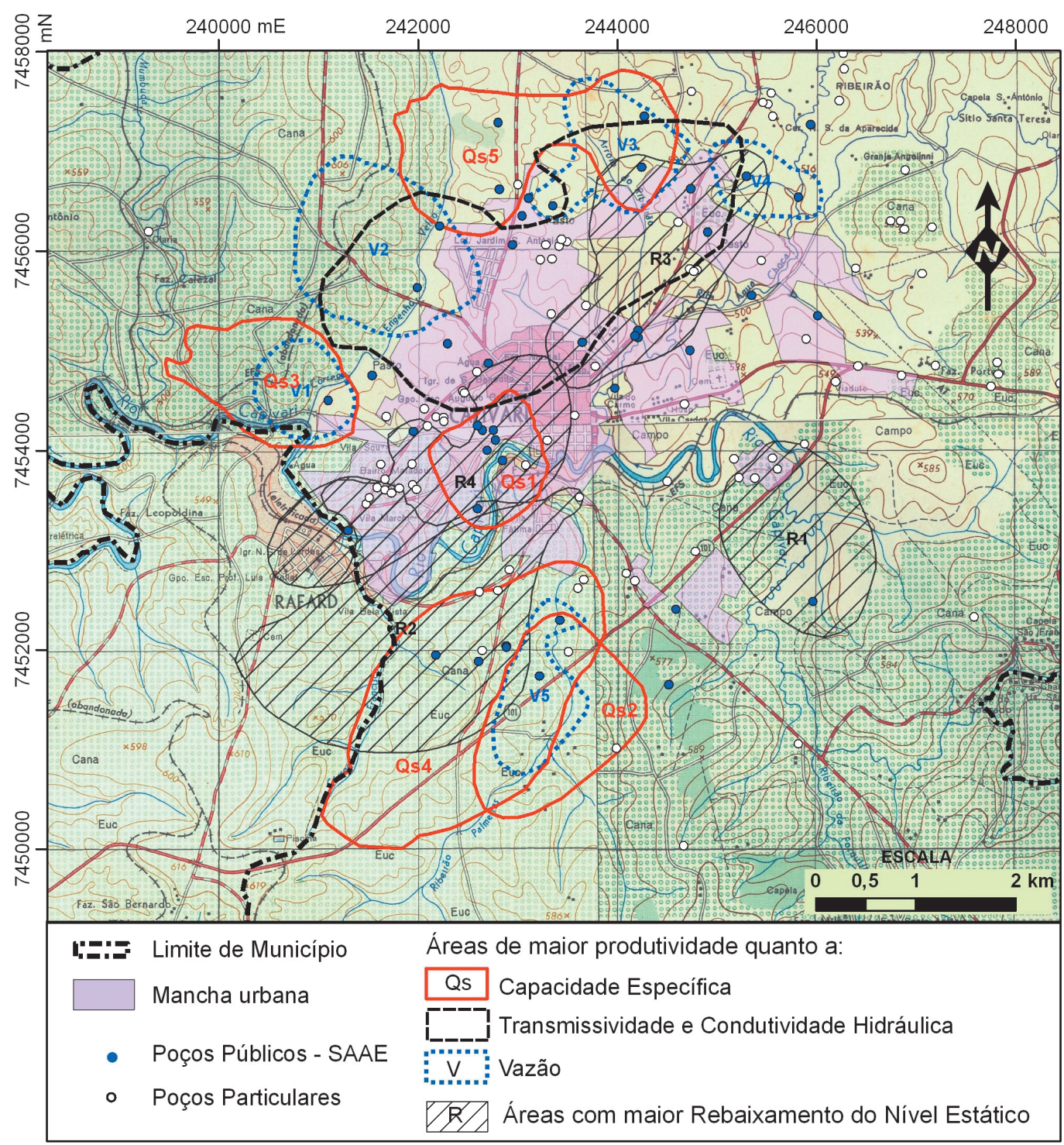

FIGURA 8 - Mapa de integração das áreas com maior produtividade e mais acentuado rebaixamento do nível da água. Base topográfica: IBGE (1970 a, b, c; 1975). 


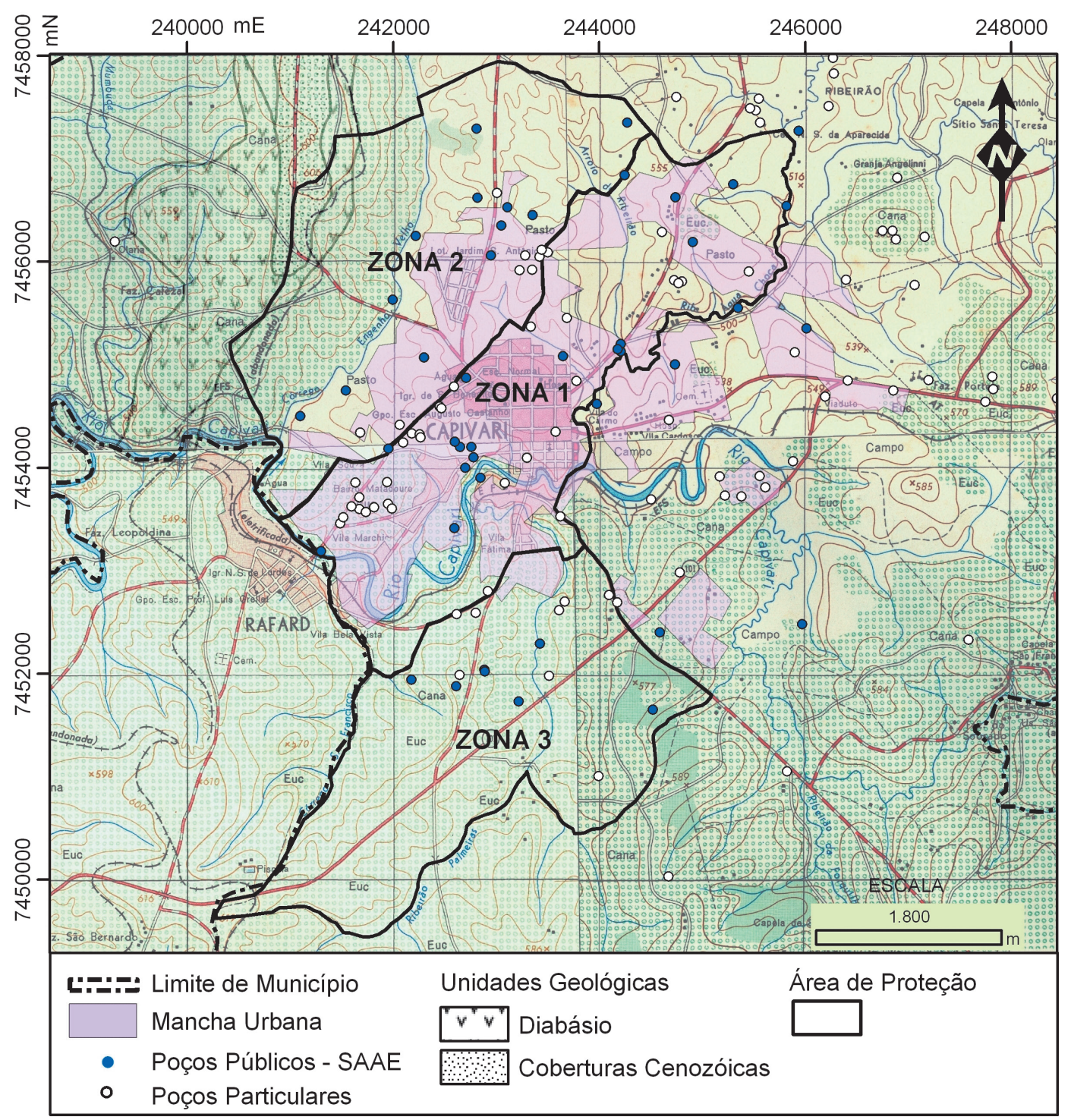

FIGURA 9 - Áreas de Proteção das águas subterrâneas em Capivari. Base topográfica: IBGE (1970 a, b, c; 1975).

Esta zona foi delimitada em função da sua melhor produtividade potencial a profundidades superiores a $250 \mathrm{~m}$ e da decorrente concentração de poços destinados ao abastecimento público. Os valores de $\mathrm{Q} / \mathrm{s}$ são superiores a $0,8 \mathrm{~m} / \mathrm{h} / \mathrm{m}$ e os de $\mathrm{T}$, superiores a $1,0 \times 10^{-4} \mathrm{~m}^{2} / \mathrm{s}$. Seu limite oeste está condicionado à ocorrência de diabásio, que pode estar atuando como uma barreira hidrogeológica, devido à sua baixa permeabilidade.

Os poços existentes não estão muito adensados e, apesar do bombeamento intensivo daqueles destinados ao sistema público de abastecimento, ainda não se observa um rebaixamento generalizado dos níveis potenciométricos.
Nesta zona ocorre grande avanço da ocupação urbana que avança sobre parte da Zona 1, especialmente na porção leste/sudeste, com tendências de expansão, implicando em dificuldade nas ações de restrição e controle das atividades existentes e do planejamento do uso do solo.

Visando evitar explotação intensiva de poços e proteger a reserva de água desta zona mais produtiva prioritariamente para uso do sistema público de abastecimento, sugere-se o controle de taxa de bombeamento de poços, público e privado, de forma que o rebaixamento de nível estático não ultrapasse $30 \mathrm{~m}$. Recomenda-se, ainda, evitar a perfuração de poços de usuários privados com mais 
de 120 metros de profundidade e de abastecimento público com profundidades inferiores a $300 \mathrm{~m}$, respeitando-se uma distância mínima de 500 metros entre poços, conforme ODA et al. (2005), exceto no caso de implantação de campo de poços.

De forma a preservar a qualidade da água subterrânea, recomenda-se o controle das atividades potencialmente poluidoras e a restrição à instalação de novos empreendimentos com alto risco de contaminação do solo, respeitando distâncias mínimas em relação aos poços destinados ao sistema público de abastecimento de água.

A Zona 3 situa-se a sul da Zona 1, estendendo-se até o Ribeirão Palmeiras. É uma área com produtividade potencial significativa e baixo índice de ocupação urbana. Ela foi delimitada considerando as isolinhas de $\mathrm{Q} / \mathrm{s}$ superiores a $0,5 \mathrm{~m}^{3} / \mathrm{h} / \mathrm{m}$ para os poços com profundidades superiores a $250 \mathrm{~m}$. Os poços com profundidades entre 150 e $250 \mathrm{~m}$ também mostraram altos valores de $\mathrm{Q} / \mathrm{s}$ (superiores a $0,8 \mathrm{~m}^{3} / \mathrm{h} / \mathrm{m}$ ), corroborando com a boa produtividade potencial desta região. Esta zona é ainda pouco explotada, há somente alguns poços de propriedade do SAAE.

Caracteriza-se como área potencial para futura explotação de água subterrânea, em função da baixa densidade populacional e pela existência de poucos poços. Este fato favorece o planejamento do uso do solo e a implantação de medidas de proteção do aqüífero com reserva de áreas destinadas a futuros poços do sistema público de abastecimento. As mesmas restrições sugeridas para a Zona 2 podem ser aplicadas para a Zona 3. Sugere-se ainda a elaboração de um plano de uso futuro da água subterrânea e estudo técnico-financeiro para delimitação de áreas reservadas para campos de poços de abastecimento público.

\section{CONCLUSÃO}

O Sistema Aqüífero Tubarão (SAT) em Capivari vem sendo explorado de forma intensiva, evidenciada pelos seguintes fatores: concentração de poços num mesmo bairro ou localidade, abandono de alguns poços motivados pela diminuição da vazão, aprofundamento de outros na tentativa de obtenção de mais água e substituições das bombas por outras mais potentes devido à queda do nível d'água.

Os mapas potenciométricos mostram uma intensificação do rebaixamento do nível estático do SAT nas últimas décadas, atingindo altitudes abaixo de $470 \mathrm{~m}$ na porção central da área urbana. Isto indica a necessidade de controle da explotação de água no município.

A avaliação do potencial do aqüífero (mapas de Q/s, T, K e vazão) demonstra produtividade média a alta em profundidades superiores a $150 \mathrm{~m}$, principalmente nas porções noroeste e sul da área urbana. Considerando a importância da água subterrânea no abastecimento da população de Capivari, é estratégico proteger as captações existentes e também essas regiões mais produtivas para garantir a produtividade de futuros poços a serem construídos.

Este estudo culminou com a delimitação de uma área de proteção para o SAT em Capivari, subdividida em três zonas conforme suas características. A área de proteção engloba as porções com maior potencial produtivo de água subterrânea, localizadas a noroeste e sul da área urbanizada (zonas 2 e 3, respectivamente) e a região com maior concentração de poços e adensamento urbano, com evidências de rebaixamento, onde as altitudes do nível d'água estão abaixo de 490 m (zona 1). Para cada uma das zonas foram sugeridas restrições e controle do uso e captação de água subterrânea, visando minimizar o impacto causado pelo bombeamento intensivo dos poços e proteger regiões do aqüífero que servirão como reservas futuras de água.

A efetiva implantação de uma área de proteção deve necessariamente envolver os órgãos gestores na definição e aplicação de procedimentos comuns e integrados de controle do uso da água e do solo.

Considerando os instrumentos legais do Estado de São Paulo, a área de proteção delimitada neste trabalho objetivou contribuir para a proposição de uma Área de Restrição e Controle, conforme estabelecida na Deliberação CRH n ${ }^{\circ}$ 52/2005.

A implantação de uma Área de Restrição e Controle é prerrogativa dos órgãos gestores ou do Comitê da Bacia Hidrográfica no qual o município se insere, podendo contar com o envolvimento da Câmara Técnica de Água Subterrânea, a fim de: a) realizar maiores discussões com outros órgãos, b) definir os limites legais desta área de proteção e as ações e procedimentos integrados para aplicação das restrições, c) organizar e promover audiências públicas de caráter consultivo com usuários e gestores, d) incluir a Área de Restrição e Controle no Plano da Bacia Hidrográfica. Concomitantemente, em nível municipal, a área de proteção deve ser considerada no Plano Diretor Municipal.

Como continuidade do estudo, recomenda-se 
a implantação de uma rede de poços de monitoramento e um controle rígido do regime de bombeamento dos poços existentes para acompanhar a evolução do comportamento do rebaixamento do nível da água e avaliar a disponibilidade do aqüífero.

É importante também que o município elabore um plano de uso da água que contemple a análise de demanda futura e a identificação de locais a serem reservados para novos poços, o que permitiria o estudo detalhado do sistema de fluxo e de disponibilidade hídrica dessas áreas.

\section{AGRADECIMENTOS}

Os autores expressam seus agradecimentos aos funcionários do SAAE - Capivari, do Departamento de Água e Energia Elétrica - DAEE, pelo fornecimento dos dados de poços para execução deste trabalho e ao FEHIDRO - Fundo Estadual de Recursos Hídricos (Contrato no 450/2006) pelo auxílio financeiro.

\section{REFERÊNCIAS BIBLIOGRÁFICAS}

ALLER, L; ENNET, T.; LEHER, J.H.; PETTY, R.J; HACKETT, G. 1987. DRASTIC: a standardized system for evaluating ground water pollution potential using hydrogeological setting. EPA, Oklahoma, EPA/600/2-87-035, $622 \mathrm{p}$.

CETESB. 2007. Relatório de qualidade das águas subterrâneas do Estado de São Paulo. Período de 2004-2006. São Paulo: CETESB, 199 p. (Série Relatórios / Secretaria de Estado do Meio Ambiente).

DAEE - DEPARTAMENTO DE ÁGUAS E ENERGIA ELÉTRICA. 1981. Estudo de águas subterrâneas, Região Administrativa 5 - Campinas. DAEE, São Paulo, 2v.

DAEE /UNESP - DEPARTAMENTO DE ÁGUAS E ENERGIA ELÉTRICA / UNIVERSIDADE ESTADUAL DO ESTADO DE SÃO PAULO. 1980. Mapeamento faciológico do Grupo Tubarão. Escala 1:50.000.

DAEE/ IG/ IPT/CPRM. 2005. Mapa de Águas Subterrâneas do Estado de São Paulo. Escala 1:1.000.000. Nota explicativa. São Paulo. São Paulo: DAEE-Departamento de Águas e Energia Elétrica, IG- Instituto Geológico, IPT-Instituto de Pesquisas Tecnológicas, CPRM-Serviço Geológico do Brasil, 3 v. (mapa e CD-ROM).

DIAS，C.L.; IRITANI, M.A.; GUILLAUMON, J.R.; CASARINI, D.C.P.; OKANO, O.; FERREIRA, L.M.R.; FRISCH; H.; TRÖGER, U.; SCHULER, G. 2004. Restrições de uso e ocupação do solo em áreas de proteção de aqüíferos: conceitos, legislação e proposta de aplicação no estado de São Paulo. In: ABAS, CONGRESSO BRASILEIRO DE ÁGUAS SUBTERRÂNEAS, 13, Cuiabá, Anais, 19 p., CD-ROM.

FERREIRA, L.M.R.; ODA, G.H.; YOSHINAGA, S.; IRITANI, M.A.; HASSUDA, S.; BERTOLO, R.A.; LOPES, M.F.C. 1996. A situação atual da exploração da água subterrânea em área de conurbação: caracterização de sua disponibilidade e uso - Região Metropolitana de Campinas - SP. In: ABAS,CONGRESSO BRASILEIRO DE ÁGUAS SUBTERRÂNEAS, 9, Salvador, Anais, 4 p.

FERREIRA, L.M.R.; IRITANI, M.A.; ODA, G.H. 2005. Proteção de aquífero no Município de Tietê - SP. In: ABAS, ENCONTRO NACIONAL DE PERFURADORES DE POÇOS, 14/ SIMPÓSIO DE HIDROGEOLOGIA DO SUDESTE, 2, Ribeirão Preto, Anais, 18 p., CD-ROM.

FOSTER, S. \& HIRATA, R. 1988. Groundwater pollution risk assessment: a methodology based on available data. WHO-PAHO/HPE-CEPIS, Lima, 81p.

FOSTER, S.; HIRATA, R.; GOMES, D.; D’ELIA, M.; PARIS, M. 2006. Proteção da qualidade da água subterrânea. Um guia para empresas de abastecimento de água, órgãos municipais e agências ambientais. Servmar, São Paulo, $104 \mathrm{p}$.

GÁRFIAS, J.; FRANCO, F; LLANOS, H. 2002. Análisis de la vulnerabilidad intrínseca y su adecuación mediante un modelo de flujo con trazado de partículas para evaluar la vulnerabilidad del Acuífero del Curso Alto del Río Lerma, Estado de México. Revista Latino-Americana de Hidrogeologia, 2: 115-126. 
HIRATA, R.C.A. 1994. Fundamentos e estratégias de proteção e controle da qualidade das águas subterrâneas: estudos de casos no Estado de São Paulo. Instituto de Geociências, Universidade de São Paulo, São Paulo, Tese de Doutorado, $195 \mathrm{p}$.

HIRATA, R.C.A. \& FERNANDES, A.J. 2008. Vulnerabilidade à Poluição de Aqüíferos. In: F.A.C. Feitosa, J. Manoel Filho, E.C. Feitosa, J.G.A Demetrio (Ed.). Hidrogeologia Conceitos e Aplicações. Rio de Janeiro, CPRM/ LABHID, p. 405-424.

IBGE - INSTITUTO BRASILEIRO DE GEOGRAFIA. 1970a. Folha Porto Feliz (SP). Carta Topográfica, Escala 1:50.000.

IBGE - INSTITUTO BRASILEIRO DE GEOGRAFIA. 1970b. Folha Capivari (SP). Carta Topográfica, Escala 1:50.000.

IBGE - INSTITUTO BRASILEIRO DE GEOGRAFIA. 1970c. Folha Salto (SP). Carta Topográfica, Escala 1:50.000.

IBGE - INSTITUTO BRASILEIRO DE GEOGRAFIA. 1975. Folha Americana (SP). Carta Topográfica, Escala 1:50.000.

IG/CETESB/DAEE - INSTITUTO GEOLÓGICO/ CETESB/DEPARTAMENTO DE ÁGUAS E ENERGIA ELÉTRICA. 1997. Mapeamento da Vulnerabilidade e Risco de poluição das águas subterrâneas do Estado de São Paulo. IG/ CETESB, São Paulo, Escala 1:1.000.000, 2v.

IG - INSTITUTO GEOLÓGICO. 1990. Subsídios do meio físico-geológico ao planejamento da região do Município de Sorocaba (SP). São Paulo, Instituto Geológico - Secretaria do Meio Ambiente, Relatório Técnico, 1v. e mapas.

IG - INSTITUTO GEOLÓGICO. 1991. Subsídios do meio físico-geológico ao planejamento do Município de Itu (SP). São Paulo, Instituto Geológico - Secretaria do Meio Ambiente, Relatório Técnico, $2 \mathrm{v}$.

IG - INSTITUTO GEOLÓGICO. 1993. Subsídios do meio físico-geológico ao planejamento do Município de Campinas (SP). Programa Cartas Geológicas e Geotécnicas para o Pla- nejamento Ambiental na Região de Sorocaba e Campinas. São Paulo, Instituto Geológico - Secretaria do Meio Ambiente, Relatório Técnico, $3 \mathrm{v}$.

IG - INSTITUTO GEOLÓGICO. 1995. Subsídios para o planejamento regional e urbano do meio físico na porção média da bacia do Rio Piracicaba. São Paulo, Instituto Geológico - Secretaria do Meio Ambiente, Relatório Técnico.

IPT - INSTITUTO DE PESQUISAS TECNOLÓGICAS. 1981. Mapa geológico do Estado de São Paulo. IPT, São Paulo, escala 1.500.000, 2 v.

IRITANI, M .A. 1998. Modelação matemática tridimensional para a proteção das captações de água subterrânea. Instituto de Geociências, Universidade de São Paulo, São Paulo, Tese de Doutorado, 200 p.

MEAULO, F. J. 2006. Mapeamento da vulnerabilidade natural à poluição dos recursos hídricos subterrâneos de Araraquara (SP). Holos Environment, 6(2): 70-90.

MERINO, L.M. \& NAVARRETE, C.M. 1991. Guía metodológica para la elaboración de perímetros de protección de captaciones de aguas subterráneas. IGME, Madrid, 289p.

NAVARRETE, C.M. \& GARCÍA, A.G. 2003. Perímetros de protección para captaciones de agua subterránea destinada al consumo humano. Metodología y aplicación al território. (Serie: Hidrogeologia y Aguas Subterráneas). IGME, Madrid, 273 p.

NRC - NATIONAL RESEARCH COUNCIL. 1993. Groundwater vulnerability assessment contamination potential under conditions of uncertainty. Committee on Techniques for Assessing Ground Water Vulnerability. Water Science and Technology Board Commission on Geosciences Environment and Resources. National Academy Press, Washington, 224p.

ODA, G.H.; BOTELHO, P.F.; IRITANI, M.A.; BERTOLO, R.A.; DINIZ, H.N. 1993. Contribuição das Águas Subterrâneas para o Abastecimento de Capivari, SP. In: ICHS, ENCONTRO NACIONAL DE ESTUDOS SOBRE O MEIO AMBIENTE, 4, Cuiabá, 
Anais, 1:381-388.

ODA, G.H.; IRITANI, M.A.; FERREIRA, L.M.R.; SILVA, A.H.; ROCHA, G.A. 2005. Proposta Metodológica para Explotação Racional do Sistema Aqüífero Tubarão no Estado de São Paulo. In: ABAS, ENCONTRO NACIONAL DE PERFURADORES DE POÇOS, 14/ SIMPÓSIO DE HIDROGEOLOGIA DO SUDESTE, 2, Ribeirão Preto, Anais, 13 p., CD-ROM.

PEREIRA, S.Y. 1997. Proposta de representação cartográfica na avaliação para estudo de planejamento e meio ambiente. Exemplo da Região Metropolitana de Campinas-SP. Instituto de Geociências, Universidade de São Paulo, São Paulo, Tese de Doutorado, 190 p.

PETRI, S. 1992. Litofácies e significado paleoambiental dos sedimentos Itararé na região $\mathrm{Ca}$ pivari- Rafard, Estado de São Paulo. Revista do Instituto Geológico, 13 (1): 7-30.

PETRI, S. \& PIRES, F.A. 1992. O Subgrupo Itararé (Permocarbonífero) na Região do Médio Tietê, Estado de São Paulo. Revista Brasileira de Geociências, 22 (3): 301-310.

PETRI, S.; VIEIRA, P. C.; ODA, G. H.; FERNANDES, P. B. 1996. O Subgrupo Itararé, Permocarbonífero da Região do Médio Tietê, Estado de São Paulo: estudos de subsuperfície. Revista do Instituto Geológico, 17 (1/2): 63-78.

PIRES, F.A. 2001. Análise paleoambiental e estratigráfica do Subgrupo Itararé na Região do Médio Tietê, Estado de São Paulo. Instituto de Geociências e Ciências Exatas, UNESP, Rio Claro, Tese de Doutorado, 117p.

PIRES, F.A. \& PETRI, S. 1991. O Subgrupo Itararé na Região Capivari-Rafard, Estado de São Paulo. In: SBG, SIMPÓSIO REGIONAL DE GEOLOGIA DO SUDESTE, 2, São Paulo, Atas, 1: 391-396.

PIRES, F.A. \& PETRI, S. 1993. Estratigrafia da Bacia do Paraná. In: FUNDUNESP, SIMPÓSIO CRONOESTRATIGRÁFICO DA BACIA DO PARANÁ, 1, Rio Claro, Boletim de Resumos, 1: 60-61.
SÃO PAULO. 1988. Lei Estadual nº 6.134, de 2 de junho de 1988, que dispõe sobre a preservação dos depósitos naturais de águas subterrâneas do Estado de São Paulo, e dá outras providências.

SÃO PAULO. 1991. Decreto Estadual no 32.955, de 07 de fevereiro de 1991. Regulamenta a Lei $n^{\circ} 6.134$, de 2 de junho de 1988.

SÃO PAULO - CONSELHO ESTADUAL DE RECURSOS HÍDRICOS. 1990. Plano Estadual de Recursos Hídricos. Primeiro Plano do Estado de São Paulo - 1990. DAEE, São Paulo, $137 \mathrm{p}$.

SÃO PAULO - CONSELHO ESTADUAL DE RECURSOS HÍDRICOS. 2005. Deliberação CRH n ${ }^{\circ}$ 052, de 15 de abril de 2005. Institui no âmbito do Sistema Integrado de Gerenciamento de Recursos Hídricos -SIGRH diretrizes e procedimentos para a definição de áreas de restrição e controle da captação e uso das águas subterrâneas.

SECRETARIA DE ECONOMIA E PLANEJAMENTO (SÃO PAULO). 1977a. Folha Rafard SF-23-Y-C-I-2-NE-B. Plano Cartográfico do Estado de São Paulo, Escala 1:10.000.

SECRETARIA DE ECONOMIA E PLANEJAMENTO (SÃO PAULO). 1977b. Folha Capivari I SF-23-Y-A-IV-4-SE-F. Plano Cartográfico do Estado de São Paulo, Escala 1:10.000.

SECRETARIA DE ECONOMIA E PLANEJAMENTO (SÃO PAULO). 1979a. Folha Capivari II SF-23-Y-A-V-3-SO-E. Plano Cartográfico do Estado de São Paulo, Escala $1: 10.000$.

SECRETARIA DE ECONOMIA E PLANEJAMENTO (SÃO PAULO). 1979b. Folha Fazenda Sobrado I SF-23-Y-C-II-1-NO-A. Plano Cartográfico do Estado de São Paulo, Escala 1:10.000.

SNIS - SISTEMA NACIONAL DE INFORMAÇÕES SOBRE SANEAMENTO/ Ministério das Cidades. 2007. Diagnóstico dos Serviços de Água e Esgoto. Disponível em http://www.snis.gov.br. 
SNIS - SISTEMA NACIONAL DE INFORMAÇÕES SOBRE SANEAMENTO / Ministério das Cidades. 2008. Diagnóstico dos Serviços de Água e Esgoto. Disponível em http:// www.snis.gov.br.

STEVAUX, J.C.; SOUZA FILHO, E. E.; LANDIN, P.M.B.; TEIXEIRA, J.A. 1987. Sistemas deposicionais do Subgrupo Itararé na bacia hidrográfica do rio Capivari, SP. In: SBG, SIMPÓSIO REGIONAL DE GEOLOGIA, 6, Rio Claro, Atas, 1: 355-374.

STROBL, R. O. \& ROBILLARD, P. D. 2005. Review of U. S. EPA - recommended and German wellhead protection area delineation methods. Journal of Environmental Hydrology, 13(3): $19 \mathrm{p}$.

USEPA - U. S. ENVIRONMENTAL PROTECTION AGENCY. 1991. Delineation of wellhead protection areas in fractured rocks. USEPA, Office of Water, Washington, EPA 570/9-91-009, $144 \mathrm{p}$.
VARNIER, C.L.; ODA. G.H.; IRITANI, M.A.; SILVA, A.H.; SILVEIRA, E.L. 2005. Caracterização hidrogeológica preliminar do Sistema Aqüífero Tubarão em Rafard e Capivari-SP. In: ABAS, ENCONTRO NACIONAL DE PERFURADORES DE POÇO, 14 / SIMPÓSIO DE HIDROGEOLOGIA DO SUDESTE, 2, Ribeirão Preto, Anais, 14 p., CD-ROM.

VIDAL, A.C. 2002. Estudo hidrogeológico do Aqüífero Tubarão na área de afloramento da porção central do Estado de São Paulo. Instituto de Geociências e Ciências Exatas, UNESP, Rio Claro, Tese de Doutorado, 122 p.

VIDAL, A.C.; ROSTIROLLA, S.E.P.; KIANG, C.H. 2005. Análise de favorabilidade para a exploração de água subterrânea na região do Médio Tietê, Estado de São Paulo. Revista Brasileira de Geociencias, 35(4): 475-481.

VRBA, J. Y \& ZAPOROZEC, A. 1994. Guide book on mapping groundwater vulnerability. Verlag Heinz Heise, Hannover, International Contributions to Hydrogeology, vol. 16, 131 p.

Endereço dos autores:

Mara Akie Iritani, Geraldo Hideo Oda, Sibele Ezaki e Cláudia Luciana Varnier - Núcleo de Hidrogeologia, Instituto Geológico, Secretaria do Meio Ambiente do Estado de São Paulo, Avenida Miguel Stéfano, 3900, Água Funda, CEP: 04301-903, São Paulo, SP. E-mails: mara.iritani@igeologico.sp.gov.br, ghoda@ igeologico.sp.gov.br, sibezaki@igeologico.sp.gov.br, claudia.varnier@igeologico.sp.gov.br 